\title{
Necrobiotic xanthogranuloma associated with smoldering multiple myeloma: satisfactory response to cyclophosphamide, dexamethasone, and thalidomide*
}

\author{
Renan Bernardes de Mello ${ }^{1}$, Everton Carlos Siviero do Vale ${ }^{1}$
}

DOI: http:/ / dx.doi.org/10.1590/abd1806-4841.20198500

Abstract: Necrobiotic xanthogranuloma is a rare chronic condition, belonging to the group C non-Langerhans cell histiocytoses, which is relevant due to the possibility of extracutaneous involvement and association with systemic diseases, particularly hematologic malignancies. The case reported here was only diagnosed after nine years of evolution and was associated with plasma cell dyscrasia. After treatment with cyclophosphamide, dexamethasone, and thalidomide, there was a reduction of cutaneous lesions and serum levels of monoclonal protein.

Keywords: Histiocytosis, non-Langerhans-Cell; Multiple myeloma; Necrobiotic xanthogranuloma; Paraproteinemias

\section{INTRODUCTION}

Necrobiotic xanthogranuloma $(\mathrm{XGN})$ is a reactive multisystemic histiocytic disease of unknown etiology, manifested by yellowish, red-orange, or brownish plaques and indurated nodules that affect the trunk, limbs, and mainly the periorbital region. ${ }^{1}$ It is a rare and difficult to control disease, characterized by refractoriness to treatment and possibility of recurrence, and which requires more consistent clinical studies.

\section{CASE REPORT}

A 48-year-old female patient was admitted to the dermatology unit with a nine-year history of yellowish papules, plaques, and nodules, with progressive growth and induration, affecting symmetrically the periorbital, mandibular, cervical, and clavicular regions, as well as armpits, back, thigh roots, hips, and legs (Figu-

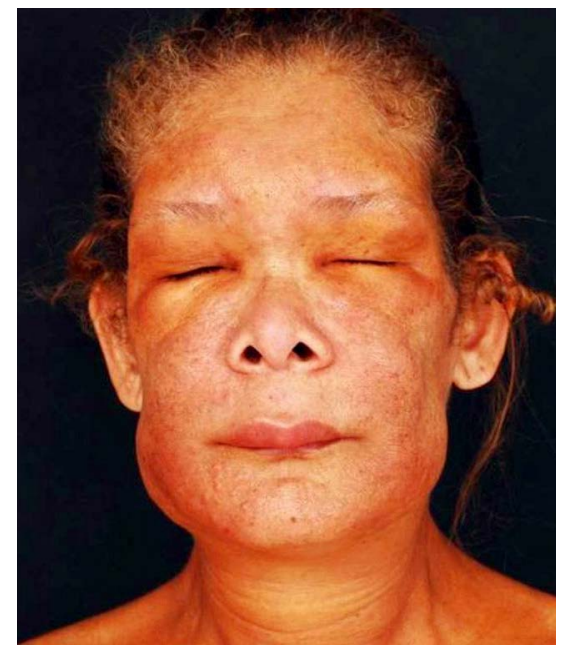

Figure 1:

Yellowish periorbital and mandibular plaques resulting in blepharoptosis; upper lip infiltration

Received 2 June 2018.

Accepted 22 November 2018.

* Study conducted at the Dermatology Service, Hospital das Clínicas, Universidade Federal de Minas Gerais, Belo Horizonte, MG, Brazil.

Financial support: None.

Conflict of Interest: None.

1 Dermatology Service, Hospital das Clínicas, Universidade Federal de Minas Gerais, Belo Horizonte, MG, Brazil.

MaILING AdDRESS:

Renan Bernardes de Mello

E-mail: bernardesrenan@yahoo.com.br 
res 1, 2, and 3). A yellowish erythematous plaque on the left leg also showed sclerosis and telangiectasias (Figure 4). The infiltrated periorbital plaques resulted in blepharoptosis and decreased visual field. Clinical examination revealed no lymph node enlargement or visceromegaly. The patient denied a history of fever, weight loss, sweating, or bone pain. A dyslipidemia in treatment with simvastatin for one year was relevant in medical history.

Altered laboratory findings included the following: hemoglobin $11.4 \mathrm{~g} / \mathrm{dL}$; MCV $76.6 \mathrm{fL}$; ferritin $16 \mathrm{ng} / \mathrm{mL}$; LDL $220 \mathrm{mg} /$ $\mathrm{dL}$; $\beta 2$-microglobulin $4.7 \mathrm{mcg} / \mathrm{mL}$ (reference value less than $2.7 \mathrm{mcg} / \mathrm{mL}$ ); ESR $125 \mathrm{~mm} / \mathrm{h}$; monoclonal peak $2.99 \mathrm{~g} / \mathrm{dL}, \mathrm{IgG} /$ kappa type. Screening for cryoglobulins and antinuclear antibodies was negative, and serum levels of calcium, C3, C4, and renal and hepatic functions were normal. The myelogram identified $13.2 \%$ plasma cells and a bone marrow biopsy confirmed the clonality (CD138+ 15\%, CD56+50\%, kappa and lambda negative). There was no evidence of osteolytic lesions on radiographs of the

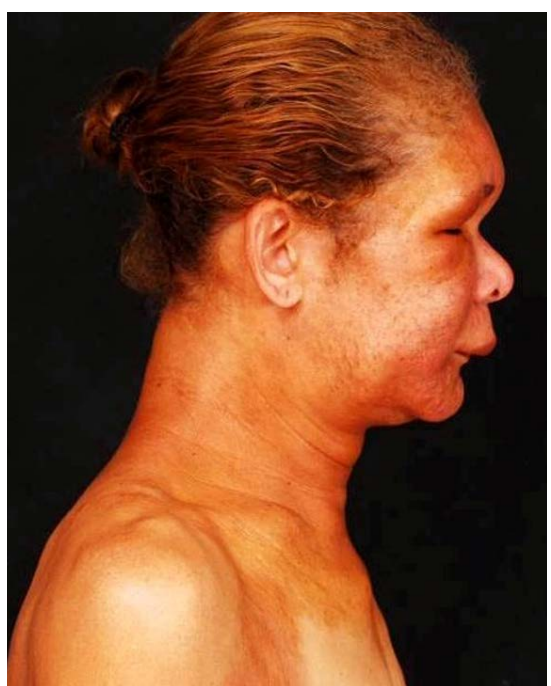

Figure 2: Symmetrical yellowish plaques in the cervical and clavicular regions skull, the long bones of the upper and lower limbs, the pelvis, and the cervical, thoracic and lumbar spine.

Histopathology of a cutaneous lesion on the back showed predominantly histiocytic inflammatory infiltrate in the deep dermis and hypodermis, besides the presence of foreign body-type and Touton-type multinucleated giant cells, foam cells, lymphoid aggregates, and degeneration of collagen fibers in the deep dermis (Figure 5); there were no cholesterol clefts. The clinical, histopathological, and laboratory findings allowed the diagnosis of necrobiotic xanthogranuloma associated with smoldering multiple myeloma. A six-month treatment was proposed with weekly cycles of $500 \mathrm{mg}$ of cyclophosphamide + $40 \mathrm{mg}$ dexamethasone and thalidomide $100 \mathrm{mg} /$ day, resulting in decreased infiltration of the cutaneous lesions (Figure 6) and reduction of serum levels of monoclonal protein.

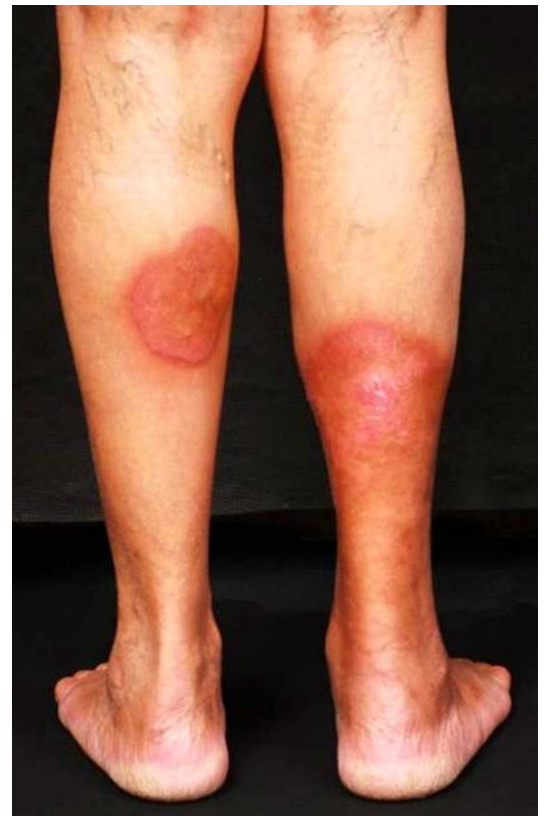

Figure 4: Circular yellowish-red plaques on the legs
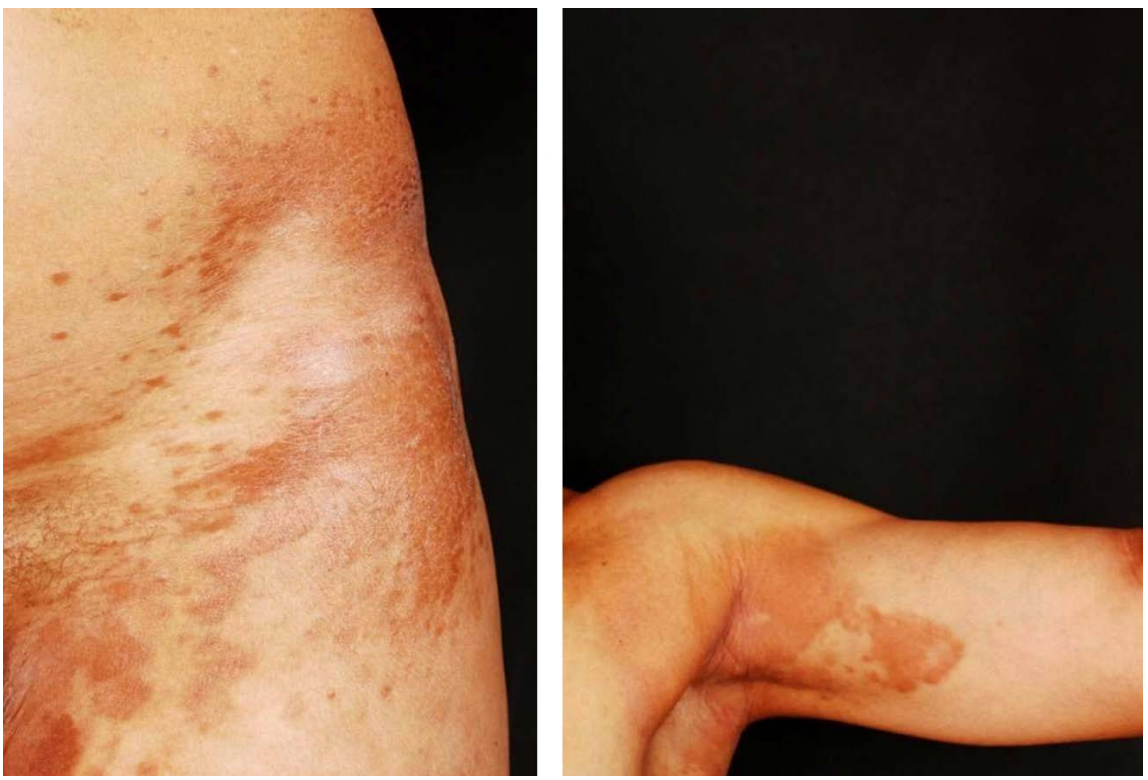

FIGURE 3: Symmetrical yellowish papules, nodules, and plaques on the hips and armpits 

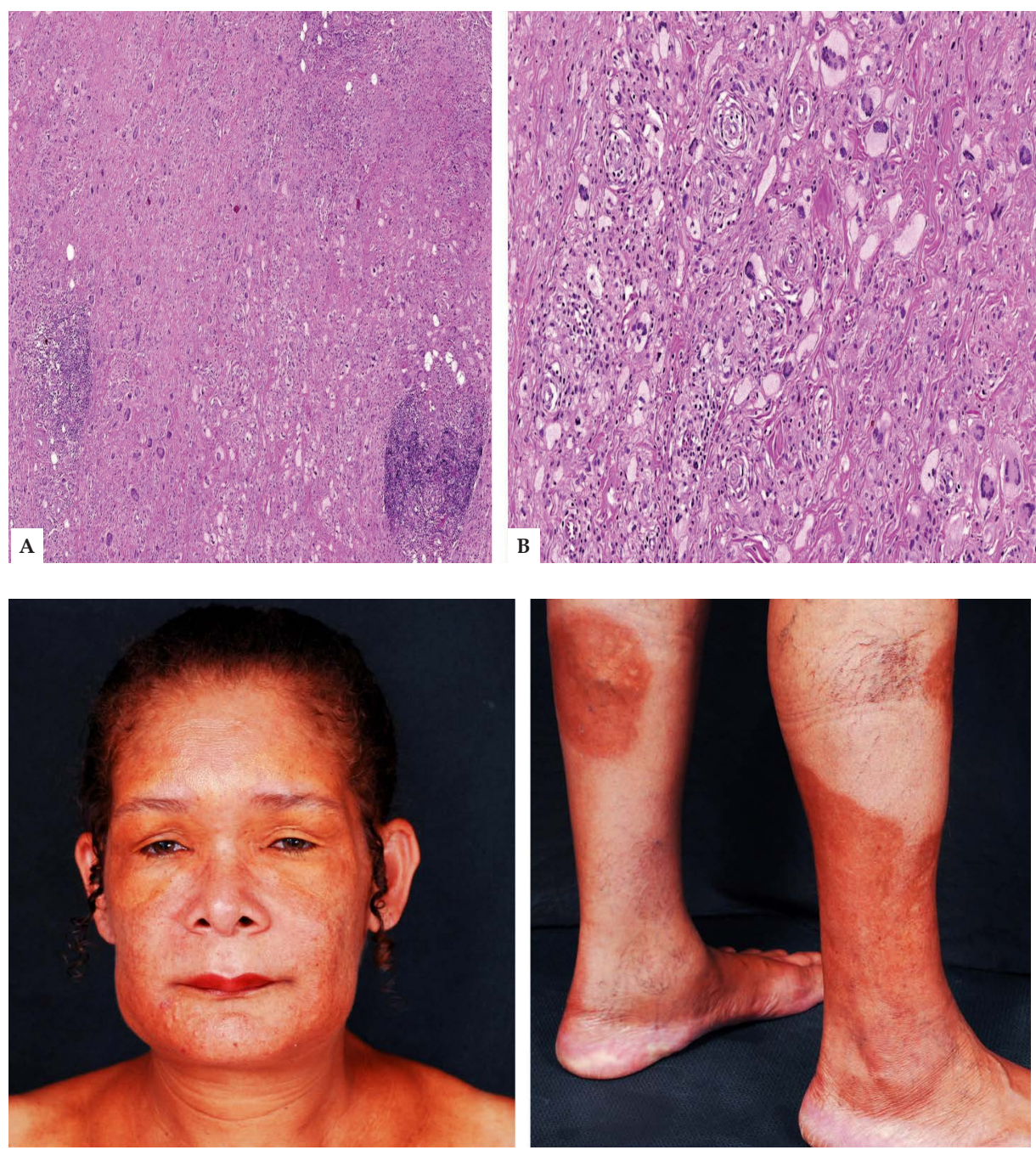

Figure 5: A - Predominantly histiocytic inflammatory infiltrate in deep dermis and hypodermis; foreign body-type and Touton-type multinucleated giant cells, as well as foam cells and lymphoid aggregates (Hematoxylin \& eosin, x200). B - Touton's cells in detail (Hematoxylin \& eosin, $x 400$ )

FIGURE 6: Reduction of infiltration of nodules and plaques after six months of chemotherapy

\section{DISCUSSION}

XGN is a rare type of group C non-Langerhans cell histiocytosis, ${ }^{2}$ which manifests by the presence of confluent papules, isolated or multiple nodules, and infiltrated plaques, yellowish-brown or purplish, with a tendency to symmetrical distribution, affecting the face, trunk, and limbs. Periorbital involvement is typical, present in approximately $80 \%$ of cases, although it is not pathognomonic nor essential for the diagnosis. ${ }^{3}$ Skin lesions may eventually arise on previous scars, as well as develop telangiectasias, ulcerations, and atrophy. ${ }^{3,4}$

In relation to the extracutaneous manifestations, there are reports of infiltration by foam cells, multinucleated foreign body cells, Touton cells, lymphoid aggregates, cholesterol clefts, and necrobiosis in the pharynx, larynx, bronchi, and lungs. Other affected organs are the eyes, which may present keratitis, uveitis, blepharoptosis, scleritis, episcleritis, and diplopia; the heart, with myocardial infiltration and pericarditis; as well as liver, skeletal muscles, bone marrow, spleen, kidneys, ovaries, intestines, paranasal sinuses, and lacrimal glands. ${ }^{1,35}$ Most of the patients have paraproteinemia (53\%-80\%), such as monoclonal gammopathy of undetermined significance, or smoldering or multiple myeloma, most commonly of the IgG/Kappa type. Other hematological diseases have also been described, such as chronic lymphocytic leukemia, Hodgkin's lymphoma, non-Hodgkin's lymphoma, Waldenström's macroglobulinemia, cryoglobulinemia, amyloidosis, and myelodysplasia. . $^{1,3,4}$

Histopathology reveals extensive degeneration of collagen and palisade granulomas. The inflammatory infiltrate is composed of lymphocytes and plasma cells of perivascular and interstitial distribution, epithelioid and foam cells, Touton and foreign-body giant cells, and atypical giant cells of bizarre shape with multiple peripheral nuclei, involving the deep dermis and often the hypodermis. The presence of lymphoid follicles and typical cholesterol clefts in the center of necrobiotic areas is also noted. ${ }^{3,5,6}$

The pathogenesis of XGN is unclear. However, one of the theories suggests that there is a foreign body-type reaction in the dermis and subcutaneous tissue to the complex formed by serum immunoglobulins with lipids. ${ }^{4}$ Another theory proposes the triggering of a xanthomatous response after binding of monoclonal proteins to receptors of lipoprotein in monocytes. ${ }^{4,6}$

Among the differential diagnoses of XGN, granuloma annulare, sarcoidosis, and necrobiosis lipoidica should be conside- 
red; differentiation between the latter can be difficult when XGN lesions are located in the pretibial region. Characteristics that disfavor the diagnosis of necrobiosis lipoidica are the association with paraproteinemias and the presence of Touton cell infiltration, cholesterol clefts, and lymphoid aggregates in histopathology. ${ }^{6}$ Periorbital XGN lesions should be distinguished from other adult orbital xanthogranulomatous diseases, as Edheim-Chester disease, adult orbital xanthogranulomatous disease, and adult-onset asthma associated with periocular xanthogranuloma. ${ }^{\text {? }}$

There is no consensus treatment, and therefore it is based on observational studies with variable responses. The most commonly used therapy relies on alkylating agents, such as chlorambucil, mel- phalan, or cyclophosphamide, sometimes combined with systemic corticosteroids, especially if there is an association with malignancies. ${ }^{8}$ Intralesional corticosteroid injection, radiotherapy, and surgical resection have been used for localized and minor lesions. Other therapeutic modalities include lenalinomide, rituximab, proteasome inhibitors, extracorporeal photopheresis, intravenous immunoglobulin, plasmapheresis, and other chemotherapeutic agents such as cladribine and vincristine. ${ }^{1,8,9}$

\section{ACKNOWLEDGEMENTS}

The authors would like to thank the medical staff of the Hematology Service, Hospital das Clínicas, Universidade Federal de Minas Gerais, for their collaboration in the follow-up of the case.

\section{REFERENCES}

1. Hilal T, DiCaudo DJ, Connolly SM, Reeder CB. Necrobiotic xanthogranuloma: a 30 year single-center experience. Ann Hematol. 2018;97:1471-9.

2. Emile JF, Abla 0, Fraitag S, Horne A, Haroche J, Donadieu J, et al. Revised classification of histiocytoses and neoplasms of the macrophage-dendritic cell lineages. Blood. 2016;127:2672-81.

3. Wood AJ, Wagner MV, Abbott JJ, Gibson LE. Necrobiotic xanthogranuloma: a review of 17 cases with emphasis on clinical and pathologic correlation. Arch Dermatol. 2009;145:279-84

4. Higgins LS, Go RS, Dingli D, Kumar SK, Rajkumar SV, Dispenzieri A, et al. Clinica features and treatment outcomes of patients with necrobiotic xanthogranuloma associated with monoclonal gammopathies. Clin Lymphoma Myeloma Leuk. 2016;16:447-52.
5. Spicknall KE, Mehregan DA. Necrobiotic xanthogranuloma. Int J Dermatol. 2009;48:1-10.

6. Fernández-Herrera J, Pedraz J. Necrobiotic xanthogranuloma. Semin Cutan Med Surg. 2007;26:108-13

7. Baykal C, Polat Ekinci A, Yazganoglu KD, Buyukbabani N. The clinical spectrum of xanthomatous lesions of the eyelids. Int J Dermatol. 2017;56:981-92.

8. Miguel D, Lukacs J, Illing T, Elsner P. Treatment of necrobiotic xanthogranuloma - a systematic review. J Eur Acad Dermatol Venereol. 2017;31:221-35.

9. Mahendran P, Wee J, Chong H, Natkunarajah J. Necrobiotic xanthogranuloma treated with lenalidomide. Clin Exp Dermatol. 2018:43:345-7.

\section{AUTHORS'CONTRIBUTIONS}

Renan Bernardes de Mello

(iD) ORCID 0000-0002-7586-0799

Conception and planning of the study; Elaboration and writing of the manuscript; Intellectual participation in propaedeutic and/or therapeutic conduct of the cases studied; Critical review of the literature, Critical review of the manuscript

Everton Carlos Siviero do Vale $\quad$ (iD) ORCID

0000-0002-9172-3639

Approval of the final version of the manuscript; Elaboration and writing of the manuscript; Effective participation in research orientation; Critical review of the literature; Critical review of the manuscript

How to cite this article: Mello RB, Vale ECS. Necrobiotic xanthogranuloma associated with smoldering multiple myeloma: satisfactory response to cyclophosphamide, dexamethasone, and thalidomide. 2019;94(3):337-40. 